\title{
Experimental hut and bioassay evaluation of the residual activity of a polymer-enhanced suspension concentrate (SC-PE) formulation of deltamethrin for IRS use in the control of Anopheles arabiensis
}

Richard M Oxborough ${ }^{1,2,3^{*}}$, Jovin Kitau ${ }^{2,3}$, Rebecca Jones ${ }^{1}$, Franklin W Mosha ${ }^{2,3}$ and Mark W Rowland ${ }^{1,3}$

\begin{abstract}
Background: The Stockholm Convention on Persistent Organic Pollutants (POPs) came into effect in 2004; the use of DDT for malaria control has been allowed to continue under exemption since then due to a perceived absence of equally effective and efficient alternatives. Alternative classes of insecticide for indoor residual spraying (IRS) have a relatively short residual duration of action (2-6 months according to WHO). In areas of year-round transmission multiple spray cycles are required, resulting in significantly higher costs for malaria control programs and user fatigue. This study evaluated performance of a new formulation of deltamethrin (pyrethroid) with polymer (SC-PE) to prolong the effective residual action to $>6$ months.

Methods: Deltamethrin SC-PE was evaluated alongside an existing water dispersible granule (WG) formulation and DDT water dispersible powder (WP) in laboratory and hut bioassays on mud, concrete, palm thatch and plywood substrates. An experimental hut trial was conducted in Lower Moshi Rice Irrigation Zone, Tanzania from 2008-2009 against wild, free-flying, pyrethroid susceptible An. arabiensis. Performance was measured in terms of insecticide-induced mortality, and blood-feeding inhibition. Bioassays were carried out monthly on sprayed substrates to assess residual activity.

Results: Bioassays in simple huts (designed for bioassay testing only) and experimental huts (designed for testing free flying mosquitoes) showed evidence that SC-PE improved longevity on mud and concrete over the WG formulation. Both deltamethrin SC-PE and WG outperformed DDT in bioassays on all substrates tested in the laboratory and simple huts. In experimental hut trials SC-PE, WG and DDT produced high levels of An. arabiensis mortality and the treatments were equivalent over nine months' duration. Marked seasonal changes in mortality were recorded for DDT and deltamethrin treatments, and may have been partly influenced by outdoor temperature affecting indoor resting duration of mosquitoes on sprayed surfaces, although no clear correlation was demonstrated.

(Continued on next page)
\end{abstract}

\footnotetext{
* Correspondence: oxandbull@hotmail.com

'Department of Disease Control, London School of Hygiene and Tropical Medicine (LSHTM), London, UK

2Department of Entomology and Parasitology, Kilimanjaro Christian Medical

University College (KCMUCo) of Tumaini University, Moshi, Kilimanjaro,

Tanzania

Full list of author information is available at the end of the article
}

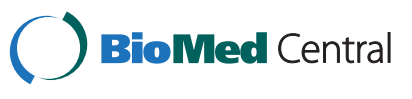

(c) 2014 Oxborough et al.; licensee BioMed Central Ltd. This is an Open Access article distributed under the terms of the Creative Commons Attribution License (http://creativecommons.org/licenses/by/4.0), which permits unrestricted use, distribution, and reproduction in any medium, provided the original work is properly credited. The Creative Commons Public Domain Dedication waiver (http://creativecommons.org/publicdomain/zero/1.0/) applies to the data made available in this article, unless otherwise stated. 
(Continued from previous page)

Conclusions: There is a limited range of alternative insecticides for IRS, and deltamethrin SC-PE is likely to have an important role as part of a rotation strategy with one or more different insecticide classes rotated annually, particularly in areas that currently have low levels of pyrethroid resistance or low LLIN coverage and year-round malaria transmission.

Keywords: IRS, Deltamethrin, Pyrethroid, Long-lasting, Anopheles arabiensis, Vector control, Malaria, Experimental hut

\section{Background}

IRS for malaria vector control has proven successful in substantially reducing transmission in a range of settings, both historically during the malaria eradication era of the 1950's and 60's, and more recently in meso- and holoendemic countries in Africa [1-3]. Interruption of malaria transmission in the USA, partly through DDT housespraying, led to the initiation of the Global Malaria Eradication Program in 1955 [4]. Enthusiasm that IRS with DDT could result in global malaria eradication led to the initiation of large-scale IRS programs in several countries. Between 1955-1978 malaria was eliminated from 37 countries, mostly in Europe and the Americas at the limits of global malaria transmission $[4,5]$.

IRS was not taken to scale in most sub-Saharan malaria endemic countries during the global eradication campaign [6,7]. Southern Africa was the exception. IRS programs using DDT began in the 1960's and were supported for several decades, with later introduction of pyrethroids and carbamates. Countries with sustained IRS activities in Africa, including South Africa, Zambia, Namibia, Swaziland, Zimbabwe and Botswana, achieved sizeable reductions in malaria vector populations and malaria incidence [7]. Focal IRS in the southern Africa region has remained important in areas of high malaria burden and areas at risk of epidemics. In 2007, about 14 million people in southern Africa were protected by IRS [6,7].

WHO has since reaffirmed the importance of IRS as a primary intervention for reducing or interrupting malaria transmission [8]. Funding for IRS in Africa has increased dramatically in recent years. The President's Malaria Initiative (PMI) was launched in 2005 as a 5-year, \$1.2 billion initiative to rapidly scale-up malaria prevention in 15 high-burden countries [9]. Mainly as a result of increased IRS funding from PMI, 8\% (58 million people) of subSaharan Africa were protected by IRS in 2012 [10]. Notable recent examples of successful malaria control using pyrethroid IRS in Africa are São Tomé and Príncipe, and Zanzibar where IRS contributed to reducing malaria prevalence to less than $1 \%$ within 2 years of the $1^{\text {st }}$ application [11,12]. Pyrethroid resistance has spread rapidly in the past decade throughout sub-Saharan Africa, and many spray programmes have switched to the use of non-pyrethroid insecticides, mainly bendiocarb and pirimiphos-methyl [13]. However, the point at which pyrethroid resistance results in control failure has yet to be demonstrated and pyrethroids may still have an important role as part of a resistance management strategy involving rotation of IRS insecticides [14].

IRS has remained the dominant vector control strategy for malaria control in India since adoption of the strategy in 1953 [10]. In 2010, IRS with diethyldiphenyltrichloroethane (DDT), malathion and pyrethroids protected 53 million people, compared with only 9.5 million protected by ITNs [15]. Global use of vector control insecticides was dominated by DDT in terms of quantity applied (71\% of total) and pyrethroids in terms of surface area covered (81\% of total) between 2000-2009 [16]. The majority of DDT was sprayed in India, with usage remaining fairly constant between 2000-2009. Globally an average of 4,429 tonnes per year of DDT was used for residual spraying vector control during this time [16]. Of the insecticides recommended by the World Health Organization Pesticide Evaluation Scheme (WHOPES) for IRS, the longestlasting is currently DDT, with duration of effective action greater than 6 months (according to WHO) [17]. The Stockholm Convention on persistent organic pollutants (2001) stipulates that, 'countries using DDT are encouraged to reduce and eliminate the use of DDT over time and switch to alternative insecticides' [18]. Despite this agreement, which became international law in 2004, global use of DDT has not changed substantially [16]. The use of DDT for malaria control has been allowed to continue under exemption since then and there is likely to be a continued role for DDT in malaria control until equally costeffective alternatives are developed [19].

Bendiocarb is a commonly used alternative to DDT and pyrethroids, but can have a relatively short residual action of 2-6 months (according to WHOPES) and costs roughly 3 times more than pyrethroids (per $100 \mathrm{~m}^{2}$ sprayed), $[17,20,21]$. In areas where the transmission season is $>6$ months, multiple spray rounds can become expensive, logistically demanding, and inconvenient to householders [8]. The residual lifespan of IRS insecticides is of key importance. LLINs have proved to be much more costeffective than IRS programs with the average IRS cost per person/yr protected of $\$ 2.62$ compared with $\$ 1.39$ for 3year duration LLINs [20]. Longer-lasting pyrethroid IRS could reduce the cost/person protected, which could in turn reduce reliance upon DDT in India. 
Despite added impetus for the development of new public health insecticides, notably from the Innovative Vector Control Consortium (IVCC), alternative classes of insecticide for public health use are emerging slowly [22]. For continued cost-effectiveness of IRS programs it is important to develop new longer-lasting formulations of currently available insecticides [23]. There are several formulation options for pesticides designed to maximize biological efficacy and reduce harmful effects [24]. Encapsulation technology has been used to extend the residual performance of current WHO recommended IRS insecticides through slow release of core active ingredients, such as lambdacyhalothrin CS [17]. A recent successful example was a new CS formulation of the organophosphate, pirimphos-methyl, which extended residual duration from 2-3 months (for the EC formulation of the same active ingredient) to 4-6 months (according to WHO), [25,26]. Polymers have also been used to extend residual performance of public health pesticides, notably for textile treatments such as the "dip-it-yourself" deltamethrin mosquito net treatment $\mathrm{K}-\mathrm{O} \mathrm{Tab}^{\oplus}$ 1-2-3 [27].

Deltamethrin wettable powder (WP) and water dispersible granules (WG) have previously been recommended by WHOPES for IRS at a dosage range of $20-25 \mathrm{mg} / \mathrm{m}^{2}$, with 3-6 months of expected duration of effective action [28]. In this study a new formulation of deltamethrin with SC-PE polymer was assessed for residual performance, with the aim being to exceed performance of the WG formulation and equal that of DDT [27].

\section{Methods}

\section{Insecticide formulations}

A new formulation of deltamethrin polymer-enhanced suspension concentrate (SC-PE) containing $62.5 \mathrm{~g}$ of active ingredient per litre (K-Othrin Polyzone ${ }^{\oplus}$, Bayer CropScience, Monheim am Rhein, Germany) was evaluated alongside the existing deltamethrin water dispersible granule (WG) $250 \mathrm{~g} / \mathrm{kg}$ (K-Othrin ${ }^{\oplus}$, Bayer CropScience, Monheim am Rhein, Germany) and DDT wettable powder (WP) $750 \mathrm{~g} / \mathrm{kg}$ (Avima, Johannesburg, South Africa).

\section{Laboratory assessment of residual performance}

Cone bioassays, based on WHO guidelines, were conducted monthly on sprayed substrates of concrete, mud, and plywood to assess insecticidal duration of deltamethrin SC-PE, WG, and DDT WP [29]. Concrete was made using a ratio of 1:2 cement:sand and left to cure for a minimum of 4 weeks. Mud was made with a ratio of 2:3 soil:sand, using soil from Lower Moshi Field Station. Petri-dish size samples of concrete, mud and plywood substrates were sprayed with insecticide at an application rate of $40 \mathrm{ml} / \mathrm{m}^{2}$ [30] using a Potter Tower Precision Sprayer (Burkard Scientific, Uxbridge, UK)
[29]. For each formulation three blocks were sprayed. Substrates were stored at ambient temperature and humidity $\left(\sim 20-28^{\circ} \mathrm{C}, 40-80 \% \mathrm{RH}\right)$. Approximately 9 replicates of $\sim 10$ female $A n$. arabiensis dondotha were tested each month with an exposure time of 30 minutes. After exposure, mosquitoes were transferred to $150 \mathrm{ml}$ paper cups with $10 \%$ glucose solution provided ad libitum. Percentage mortality was scored after $24 \mathrm{~h}$. An. arabiensis dondotha adult mosquitoes were insectary reared under controlled conditions of $22-27^{\circ} \mathrm{C}$ and $60-85 \%$ relative humidity. They were fully susceptible to deltamethrin when tested in WHO cylinder tests $(100 \%$ mortality, deltamethrin $0.05 \%, \mathrm{n}=100$ ).

\section{Field assessment of residual performance in simple huts}

Simple huts were built corresponding to the design of experimental huts, minus the verandas [31]. The walls were lined with four types of material, with one material per wall surface: mud, concrete, plywood, palm thatch. There was an eave space, small windows and wooden ceiling to allow for ventilation and prevent extreme temperatures. Each spray treatment was tested using cone bioassays of insectary reared $A n$. arabiensis 3-7 days after spraying and subsequently every month. Cones were randomly positioned every month and testing was done in the morning (06:30 - 10:00) when testing conditions were most suitable (i.e. humidity $>60 \% \mathrm{RH}$, temperature $<28^{\circ} \mathrm{C}$ ). Mosquitoes were transferred to paper cups with access to $10 \%$ glucose solution and kept in the field station holding room with mortality recorded $24 \mathrm{~h}$ after testing.

The following treatments were sprayed in vertical swaths $71 \mathrm{~cm}$ wide marked with chalk on simple hut walls plastered with mud, concrete, palm thatch and plywood.

Deltamethrin SC-PE, $50 \mathrm{mg}$ ai $/ \mathrm{m}^{2}$, (subsequently

abbreviated to delta SC-PE 50)

Deltamethrin SC-PE, $25 \mathrm{mg}$ ai $/ \mathrm{m}^{2}$, (subsequently

abbreviated to delta SC-PE 25)

Deltamethrin WG, $25 \mathrm{mg}$ ai $/ \mathrm{m}^{2}$, (subsequently

abbreviated to delta WG 25)

DDT WP, $2000 \mathrm{mg}$ ai $/ \mathrm{m}^{2}$, (subsequently abbreviated to DDT WP)

Unsprayed

The walls were sprayed following the same protocol as the experimental huts. The duration of the vertical spray motion from ceiling to floor to achieve the required application rate was timed precisely and much practised by the spray person before he delivered the swath with the formulation at the requisite concentration.

\section{Indoor residual spraying experimental hut trials}

Experimental hut trials were conducted at Kilimanjaro Christian Medical University College (KCMUCo) Harusini 
Field Station in Lower Moshi Rice Irrigation Zone ( $3^{\circ} 24^{\prime} \mathrm{S}$, $37^{\circ} 21^{\prime} \mathrm{E}$ ) where wild $A n$. arabiensis and $C x$. quinquefasciatus were the predominant man-biting mosquito species [32]. $A n$. arabiensis densities were heavily dependent on rice cropping cycles. Wild An. arabiensis were tested in WHO cylinder tests with diagnostic dosages of permethrin, deltamethrin, lambdacyhalothrin and DDT papers (Vector Control Research Unit, Universiti Sains Malaysia) in April 2009, and a low frequency of resistance was detected (Table 1).

Experimental huts were constructed to a design described by the World Health Organization [29] and based on the original veranda hut design constructed in northern Tanzania [33,34]. Improvements were made involving a) reduction of eave gap to $5 \mathrm{~cm}, \mathrm{~b}$ ) addition of inner ceiling board, c) concrete floor surrounded by a water filled moat [35]. The working principle of these huts has been described previously [31]. The experimental huts had either mud or concrete walls prepared to the specifications of laboratory blocks and simple hut walls. A palm thatched mat, typical of organic fibres used in some rural housing [36], was affixed to the ceiling before spraying. The walls and ceiling were sprayed with a Hudson sprayer (H.D. Hudson Manufacturing Company, Chicago, Illinois, USA) at an application rate of $40 \mathrm{ml} / \mathrm{m}^{2}$ [30]. A guidance pole was used to ensure a consistent vertical swath $71 \mathrm{~cm}$ wide and swath boundaries were marked out with chalk on walls and ceiling to improve spray accuracy. Verandas were protected during spraying by blocking the open eaves and windows with a double layer of plastic and Hessian sackcloth. A limitation was that no high performance liquid chromatography (HPLC) was conducted to confirm the dosages sprayed. However, the amount of insecticide remaining in the spray tank after spraying each hut indicated that application rates were within $20 \%$ of the target.

Ethical approval was granted from the review boards of LSHTM and Tanzania National Institute of Medical Research (NIMR/HQ/R.8c/Vol.I/24). Adult volunteers of 18 years or older were selected as volunteers from the local village to sleep in the huts overnight. The risks of malaria were explained and volunteers were provided with chemoprophylaxis, but taking was not enforced or observed. During the trial each volunteer was monitored daily for fever or possible adverse effects due to the IRS.

Table $1 \%$ mortality of wild collected semi-gravid An. arabiensis collected from surrounding cattle sheds

\begin{tabular}{llll}
\hline Insecticide & Concentration $\%$ & Number tested & Mortality \% \\
\hline Deltamethrin & 0.05 & 275 & 90 \\
Permethrin & 0.75 & 111 & 84 \\
Lambdacyhalothrin & 0.05 & 77 & 97 \\
DDT & 4 & 465 & 99 \\
\hline
\end{tabular}

Written informed consent was obtained from all volunteer sleepers and documented. Volunteers were given basic remuneration for participating in the study. It was explained they had the right to withdraw from the trial at any time without penalty. Adult volunteers slept in each hut nightly from 20:30-6:30. Sleepers were rotated between huts on successive nights to reduce any bias due to differences in individual attractiveness to mosquitoes. Mosquito collections were carried out using mouth aspirators between 6:30-08:00 each morning by trained field assistants. White sheets were laid on the concrete floor to make dead mosquitoes more easily visible. Dead mosquitoes were collected from the floor of verandas, window traps and bedroom. Live mosquitoes in the sprayed room were not collected in order to allow for natural resting times on treated surfaces, and were only collected after exiting to verandas or window traps. Live mosquitoes were transferred to $150 \mathrm{ml}$ paper cups and provided with $10 \%$ glucose solution for scoring gonotrophic status and delayed mortality after $24 \mathrm{~h}$. All members of the An. gambiae species complex identified by morphological characteristics were assumed to be $A n$. arabiensis based on PCR identification between 20052013, which showed the absence of An. gambiae s.s. [37-40].

The following treatments were sprayed in a total of 7 experimental huts.

Deltamethrin SC-PE, $25 \mathrm{mg} / \mathrm{m}^{2}$ (one mud and one concrete walled hut)

Deltamethrin WG, $25 \mathrm{mg} / \mathrm{m}^{2}$ (one mud and one concrete walled hut)

DDT WP, $2000 \mathrm{mg} / \mathrm{m}^{2}$ (one mud and one concrete walled hut)

Unsprayed (one mud walled hut)

\section{Analysis of residual performance in the laboratory}

Treatments were compared according to the time interval since spray application for mortality to fall to $80 \%$ (based on WHOPES criteria) and 50\% [29]. Mixed effect logistic regression models were used to fit mortality trajectories over time separately for each treatment (delta SC-PE $25 \mathrm{mg} / \mathrm{m}^{2}$, delta SC-PE $50 \mathrm{mg} / \mathrm{m}^{2}$, delta WG $25 \mathrm{mg} / \mathrm{m}^{2}$, and DDT WP $2000 \mathrm{mg} / \mathrm{m}^{2}$ ) and substrate (concrete and mud). All statistical modelling was performed on the log odds scale at the individual mosquito level and results back transformed to the proportion scale. There was little evidence of a departure from a linear decrease in the log odds of death over time so a linear term in time was specified as the only predictor in all models. A random effect was specified in all models to account for similarities in mosquitoes tested at the same time point and for potential behavioural clustering within the same test batch. The equations given by the estimates from the logistic 
regression models were solved to obtain estimates of the time points at which mortality fell to 80 and $50 \%$. Ninetyfive per cent confidence intervals (CI) were estimated using the bias corrected bootstrap method with 2,000 replications. Differences between treatments in estimated time for mortality to fall to 80 and $50 \%$ were calculated and statistically significant differences inferred from the bootstrap 95\% CI ( $\mathrm{p}=0.05)$.

\section{Analysis of simple hut and experimental hut bioassays}

Analysis of hut bioassays was similar to that described for laboratory bioassays. For wall assays, separate models were fitted for each hut. For ceiling assays, data from huts treated with the same insecticide (but with different wall materials) were combined.

\section{Analysis of experimental hut trial}

The number of mosquitoes collected from the two closed verandas was multiplied by two to adjust for the unrecorded escapes through the two open verandas which were left unscreened to allow routes for entry of wild mosquitoes via the gaps under the eaves $[9,24]$. The data were analysed to show the effect of each treatment in terms of:

Overall mortality $=$ Total proportion of mosquitoes dead on the morning of collection, plus delayed mortality after holding for a total of 24 hours.

Blood feeding inhibition = Percentage of blood-fed mosquitoes from a treated hut relative to percentage from the unsprayed negative control.

Mixed effect logistic regression models were used to fit mortality trajectories over time. All statistical modelling was performed on the log odds scale. The main predictors were hut treatment (each of delta SC-PE $25 \mathrm{mg} / \mathrm{m}^{2}$, delta WG $25 \mathrm{mg} / \mathrm{m}^{2}$ and DDT WP $2000 \mathrm{mg} / \mathrm{m}^{2}$ on both mud and concrete), polynomial terms in time, and interactions between treatment and each of the time terms. Modelling was done for the supplementary explanatory experimental hut studies with the added predictor of covering and uncovering the palm thatch ceiling. Mean indoor and outdoor overnight temperature and humidity were added as covariates in order to examine possible associations between mortality and climate factors. All models were adjusted for sleeper and included a random effect to account for similarities among mosquitoes entering huts on the same day and potential behavioural clustering.

\section{Results}

Laboratory (mud, concrete), simple hut (mud, concrete), and experimental hut (mud, concrete, palm thatch) bioassay results indicating the duration of residual activity of the deltamethrin and DDT formulations are presented in Table 2. The differences in longevity are shown in
Table 3, showing residual time (RT) taken for mortality to drop below 80\% (RT 80) and 50\% (RT 50).

\section{Laboratory assessment of residual performance}

On mud, delta SC-PE $25 \mathrm{mg} / \mathrm{m}^{2}$ killed $>80 \%$ of $A n$. arabiensis for 8.3 months (95\% CI: 7.5-9.1), but performed no better than the WG formulation $(p>0.05)$. Both SC$\mathrm{PE}$ and WG formulations provided greater residual performance than DDT, which killed $>80 \%$ for only 5.2 months (95\% CI: 4.4-5.9). Delta SC-PE $50 \mathrm{mg} / \mathrm{m}^{2}$ lasted significantly longer than the SC-PE 25 and WG 25 treatments, with $>80 \%$ mortality achieved for 13.4 months, $(12.8-14.3)(\mathrm{p}<0.05)$ (Figure 1).

On concrete, delta SC-PE 25 killed $>80 \%$ of $A n$. arabiensis for 15.5 months (95\% CI: 14.5-17.3), but performed no better than the WG formulation ( $p>0.05)$. Both the SC-PE 25 and WG 25 lasted longer than DDT ( $\mathrm{p}<0.05)$, which killed $>80 \%$ for only 10.1 months $(95 \%$ CI: 8.9-11.4). Statistical comparison with SC-PE 50 could not be made as mortality remained above $80 \%$ for the duration of the study (Figure 2). On plywood, all formulations killed $>95 \%$ of $A n$. arabiensis 16 months after spraying (data not presented).

\section{Field assessment of residual performance in simple huts}

RT80 is not presented for formulations sprayed on mud as mortality was already below $80 \%$ when bioassays were conducted $<1$ week after spraying (Table 2). Delta SC-PE 25 killed $>50 \%$ of An. arabiensis for 6.0 months (95\% CI: 5.06.9) and lasted significantly longer than the WG $(\mathrm{p}<0.05)$ but was no different to the SC-PE 50 ( $p>0.05$ ). Mortality for DDT was $<50 \%<1$ week after spraying and was not included in the analysis.

On concrete, delta SC-PE 25 killed $>80 \%$ of $A n$. arabiensis for 8.0 months (95\% CI: 6.7-9.0) and $>50 \%$ for 12.4 months (95\% CI: 11.3-13.9) and lasted significantly longer than the WG which only killed $>50 \%$ for 2.1 months $(\mathrm{p}<0.05)$ (Table 3). The SC-PE 50 lasted longer than both SC-PE 25 and WG 25 ( $\mathrm{p}<0.05)$. Mortality for DDT was surprisingly low and neither RT 80 nor 50 could be estimated.

Bioassays done on plywood and palm thatch produced very high levels of mortality for all deltamethrin formulations, with little loss of activity over the duration of the trial; therefore analysis of RT 80 and RT 50 was not done. On plywood, observed mortality was $>80 \%$ for SC-PE 25 and WG 25 for 12 months and 18 months for SC-PE 50. On palm thatch observed mortality for SC-PE 25 and WG 25 was $>80 \%$ for 14 months, compared with 18 months for SC-PE 50, while DDT produced surprisingly low levels of observed mortality with $>80 \%$ for only 2 months.

\section{Residual activity of formulations in experimental huts}

WHO cone bioassays on walls of experimental huts showed consistently higher mortality for all formulations 
Table 2 Time for mortality to drop below $\mathbf{8 0} \%$ and $\mathbf{5 0 \%}$ for laboratory, simple hut, and experimental hut bioassays

\begin{tabular}{|c|c|c|c|c|c|}
\hline \multirow[t]{2}{*}{ Substrate } & \multirow[t]{2}{*}{ Insecticide } & \multicolumn{2}{|c|}{ Estimated time to $80 \%$ mortality } & \multicolumn{2}{|c|}{ Estimated time to $\mathbf{5 0} \%$ mortality } \\
\hline & & Time (months) & $95 \% \mathrm{Cl}$ & Time (months) & $95 \% \mathrm{Cl}$ \\
\hline \multicolumn{6}{|c|}{ Laboratory bioassays } \\
\hline \multirow[t]{4}{*}{ Mud } & Delta SC-PE 50 & 13.4 & (12.8 to 14.3$)$ & 15.8 & (15.0 to 17.1$)$ \\
\hline & Delta SC-PE 25 & 8.3 & (7.5 to 9.1$)$ & 11.6 & (10.9 to 12.4$)$ \\
\hline & Delta WG 25 & 8.1 & (7.6 to 8.7 ) & 10.9 & (10.4 to 11.4$)$ \\
\hline & DDT WP 2000 & 5.2 & (4.4 to 5.9$)$ & 8.4 & (7.8 to 9.0 ) \\
\hline \multirow[t]{4}{*}{ Concrete } & Delta SC-PE 50 & $\dagger$ & $\dagger$ & $\dagger$ & $\dagger$ \\
\hline & Delta SC-PE 25 & 15.5 & (14.5 to 17.3$)$ & $\dagger$ & $\dagger$ \\
\hline & Delta WG 25 & 14.9 & (13.8 to 16.9$)$ & $\dagger$ & $\dagger$ \\
\hline & DDT WP 2000 & 10.1 & (8.9 to 11.4$)$ & 14.6 & (13.3 to 16.6$)$ \\
\hline \multicolumn{6}{|c|}{ Simple hut bioassays } \\
\hline \multirow[t]{3}{*}{ Mud } & Delta SC-PE 50 & $\dagger$ & $\dagger$ & 4.6 & $(2.4$ to 6.0$)$ \\
\hline & Delta SC-PE 25 & t & $\dagger$ & 6.0 & (5.0 to 6.9$)$ \\
\hline & Delta WG 25 & $\dagger$ & $\dagger$ & 2.6 & (0.3 to 4.1$)$ \\
\hline \multirow[t]{3}{*}{ Concrete } & Delta SC-PE 50 & 11.2 & (10.4 to 12.1$)$ & 14.7 & (13.7 to 16.0$)$ \\
\hline & Delta SC-PE 25 & 8.0 & (6.7 to 9.0$)$ & 12.4 & (11.3 to 13.9$)$ \\
\hline & Delta WG 25 & t & + & 2.1 & (tto 3.6) \\
\hline \multicolumn{6}{|c|}{ Experimental hut bioassays } \\
\hline \multirow[t]{3}{*}{ Mud } & Delta SC-PE 25 & 2.8 & $(0.2$ to 4.6$)$ & 8.0 & (6.7 to 9.2 ) \\
\hline & Delta WG 25 & $\dagger$ & $\dagger$ & 0.5 & (tto 3.0) \\
\hline & DDT WP 2000 & t & + & 3.3 & (1.1 to 5.0$)$ \\
\hline \multirow[t]{3}{*}{ Concrete } & Delta SC-PE 25 & 11.4 & (9.2 to 16.7 ) & $\dagger$ & $\dagger$ \\
\hline & Delta WG 25 & 5.8 & (0.8 to 8.2$)$ & $\dagger$ & $\dagger$ \\
\hline & DDT WP 2000 & 7.0 & (4.3 to 8.9$)$ & 12.0 & (10.4 to 15.1$)$ \\
\hline
\end{tabular}

Notes: + indicates that statistical models produced estimates outside the study period.

on concrete than on mud. On mud, only RT 50 was compared as mortality dropped below $80 \%$ shortly after spraying. The SC-PE 25 killed $>50 \%$ of An. arabiensis for 8.0 months (95\% CI: 6.7-9.2) and showed greater longevity than WG which produced an RT50 of only 0.5 months $(95 \% \mathrm{CI}: \dagger-3.0)$ and DDT $(\mathrm{p}<0.05)$ (Table 3, Figures 3, and 4).

On concrete, the SC-PE 25 formulation was the longest lasting and killed $>80 \%$ of An. arabiensis for 11.4 months (95\% CI: 9.2-16.7) compared with 5.8 months for WG (95\% CI: 0.8-8.2) and 7.0 months for DDT (95\% CI: 4.3-8.9) $(\mathrm{p}<0.05)$ (Table 2, and 3; Figures 3, and 4).

Observed and predicted mortality curves are presented in Figure 5 for bioassays on sprayed palm thatch ceiling in experimental huts. As in simple hut bioassays, mortality was stable and no loss of activity was recorded for the SC-PE 25, up to14 months after spraying (Figure 5). DDT and delta WG followed a similar trajectory but showed a slight decrease in mortality between 6 and 14 months, although mortality was still $>60 \%$ after 14 months.
Experimental hut trial against wild, free flying, An. arabiensis over 9 months to compare efficacy of DDT and deltamethrin formulations

Mortality of free-flying, wild An. arabiensis showed an unusual trend during the course of the trial and peaked 4 months after spraying (Figure 6). Mortality of wild $A n$. arabiensis during the first month after spraying was relatively low for all treatments (40-55\% across treatments). Mortality rates continued to fall over the next three months (April-June). Four months after spraying (July) mortality rates suddenly increased and reached a peak with 75\% (95\% CI: 70-80) (mud) and 80\% (95\% CI: 75-84) (concrete) mortality recorded for delta SC-PE 25 (Table 4). Between 5-9 months after spraying (August-December) there was a gradual decrease in mortality for all treatments with mortality $<45 \%$ nine months after spraying. There was no evidence of any effect of treatment on mortality trajectories over time $(\mathrm{P}>0.05)$ although there was weak evidence that average mortality levels were slightly higher in concrete than mud huts $(\mathrm{p}=0.071)$. Rather more expectedly, cone bioassay results on hut walls showed 
Table 3 Comparison of treatments for mortality to drop below $\mathbf{8 0} \%$ and $\mathbf{5 0} \%$ for laboratory, simple hut, and experimental hut bioassays

\begin{tabular}{|c|c|c|c|c|c|c|c|}
\hline \multirow[t]{2}{*}{ Substrate } & \multirow{2}{*}{$\begin{array}{l}\text { Treatment } \\
\text { comparison }\end{array}$} & \multicolumn{3}{|c|}{ Difference in estimated time to $80 \%$ mortality } & \multicolumn{3}{|c|}{ Difference in estimated time to $50 \%$ mortality } \\
\hline & & Time (months) & $95 \% \mathrm{Cl}$ & P-value & Time (months) & $95 \% \mathrm{Cl}$ & P-value \\
\hline \multicolumn{8}{|c|}{ Laboratory Bioassays } \\
\hline \multirow[t]{6}{*}{ Mud } & SC-PE 50 vs SC-PE 25 & 5.0 & $(4.0$ to 6.2$)$ & $<0.05$ & 4.2 & (3.0 to 5.6$)$ & $<0.05$ \\
\hline & SC-PE 50 vS WG & 5.3 & $(4.4$ to 6.3$)$ & $<0.05$ & 4.9 & $(4.0$ to 6.2$)$ & $<0.05$ \\
\hline & SC-PE 50 vs DDT & 8.2 & (7.2 to 9.4$)$ & $<0.05$ & 7.4 & $(6.4$ to 8.7$)$ & $<0.05$ \\
\hline & SC-PE 25 vs WG & 0.2 & $(-0.8$ to 1.2$)$ & $n / s$ & 0.7 & $(-0.1$ to 1.6$)$ & $n / s$ \\
\hline & SC-PE 25 vs DDT & 3.2 & $(2.1$ to 4.3$)$ & $<0.05$ & 3.2 & (2.3 to 4.3$)$ & $<0.05$ \\
\hline & WG vs DDT & 2.9 & (2.0 to 3.9$)$ & $<0.05$ & 2.5 & (1.7 to 3.2$)$ & $<0.05$ \\
\hline \multirow[t]{3}{*}{ Concrete } & SC-PE 25 vS WG & 0.6 & $(-1.5$ to 2.5$)$ & $n / s$ & $\dagger$ & $\dagger$ & $\dagger$ \\
\hline & SC-PE 25 vs DDT & 5.4 & (3.8 to 7.3 ) & $<0.05$ & $\dagger$ & $\dagger$ & $\dagger$ \\
\hline & WG vs DDT & 4.8 & (3.0 to 6.8 ) & $<0.05$ & t & $\dagger$ & $\dagger$ \\
\hline \multicolumn{8}{|c|}{ Simple Hut Bioassays } \\
\hline \multirow[t]{3}{*}{ Mud } & SC-PE 50 vs SC-PE 25 & $\dagger$ & $\dagger$ & $\dagger$ & -1.4 & (0.4 to -3.7$)$ & $n / s$ \\
\hline & SC-PE 50 vs WG & $\dagger$ & $\dagger$ & $\dagger$ & 2.0 & $(-0.5$ to 4.5$)$ & $n / s$ \\
\hline & SC-PE 25 VS WG & $\dagger$ & $\dagger$ & $\dagger$ & 3.4 & (1.6 to 5.9$)$ & $<0.05$ \\
\hline \multirow[t]{3}{*}{ Concrete } & SC-PE 50 vs SC-PE 25 & 3.2 & (1.8 to 4.7$)$ & $<0.05$ & 2.3 & (0.5 to 4.0$)$ & $<0.05$ \\
\hline & SC-PE 50 vS WG & $\dagger$ & $\dagger$ & $\dagger$ & 12.6 & (10.6 to 15.1$)$ & $<0.05$ \\
\hline & SC-PE 25 VS WG & $\dagger$ & t & + & 10.3 & (8.3 to 13.0 ) & $<0.05$ \\
\hline \multicolumn{8}{|c|}{ Experimental Hut Bioassays } \\
\hline \multirow[t]{3}{*}{ Mud } & SC-PE 25 VS WG & $\dagger$ & $\dagger$ & $\dagger$ & 7.5 & (4.4 to 13.8$)$ & $<0.05$ \\
\hline & SC-PE 25 vs DDT & t & $\dagger$ & † & 4.7 & (2.6 to 7.2$)$ & $<0.05$ \\
\hline & WG vs DDT & $\dagger$ & $\dagger$ & $\dagger$ & -2.8 & $(-9.9$ to 0.5$)$ & $n / s$ \\
\hline \multirow[t]{3}{*}{ Concrete } & SC-PE 25 VS WG & 5.7 & (1.9 to 11.6$)$ & $<0.05$ & $\dagger$ & $t$ & $\dagger$ \\
\hline & SC-PE 25 vs DDT & 4.4 & (1.3 to 9.5$)$ & $<0.05$ & + & + & † \\
\hline & WG vs DDT & -1.2 & $(-5.9$ to 2.4$)$ & $n / s$ & t & $\dagger$ & $\dagger$ \\
\hline
\end{tabular}

Notes: + indicates that statistical models produced estimates outside the study period.

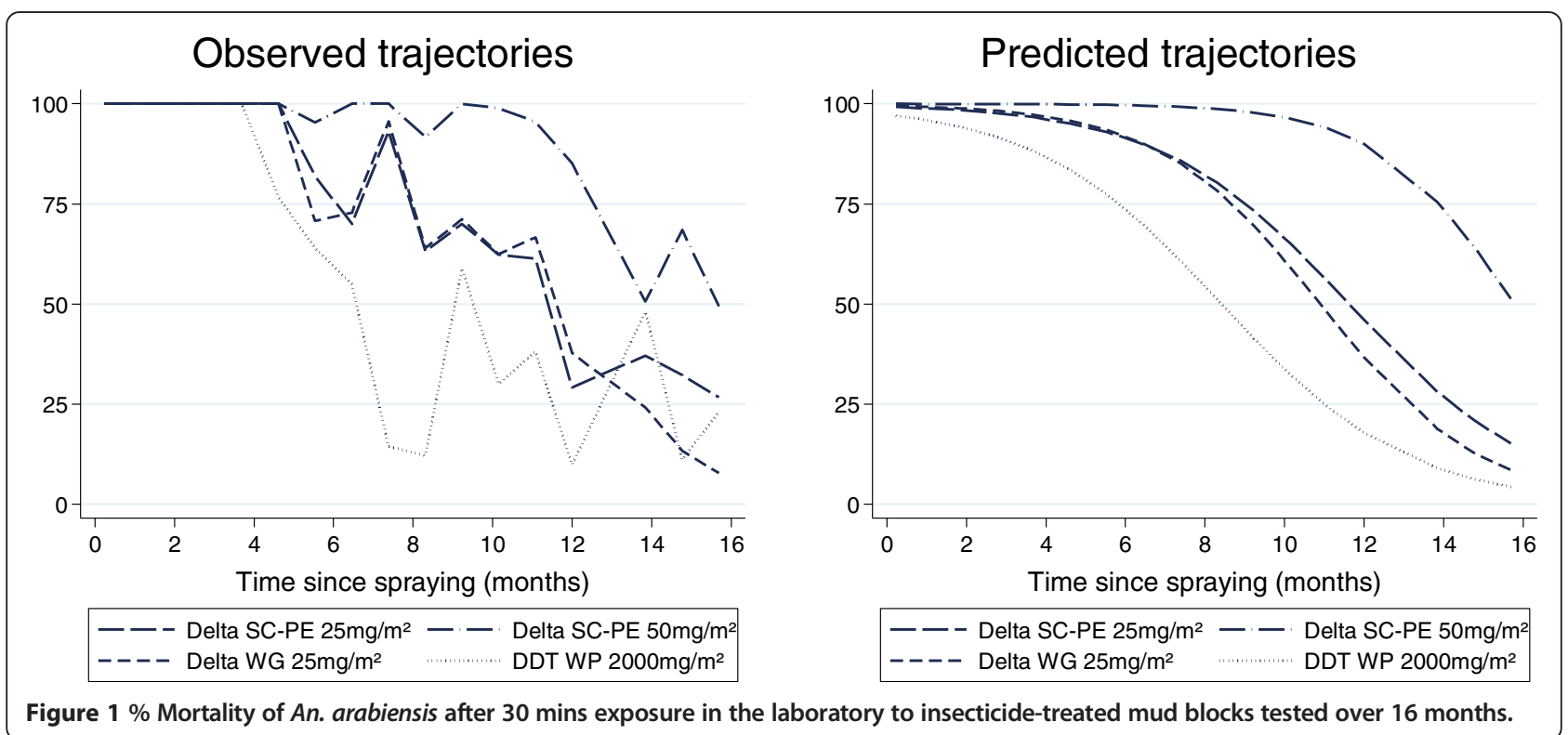




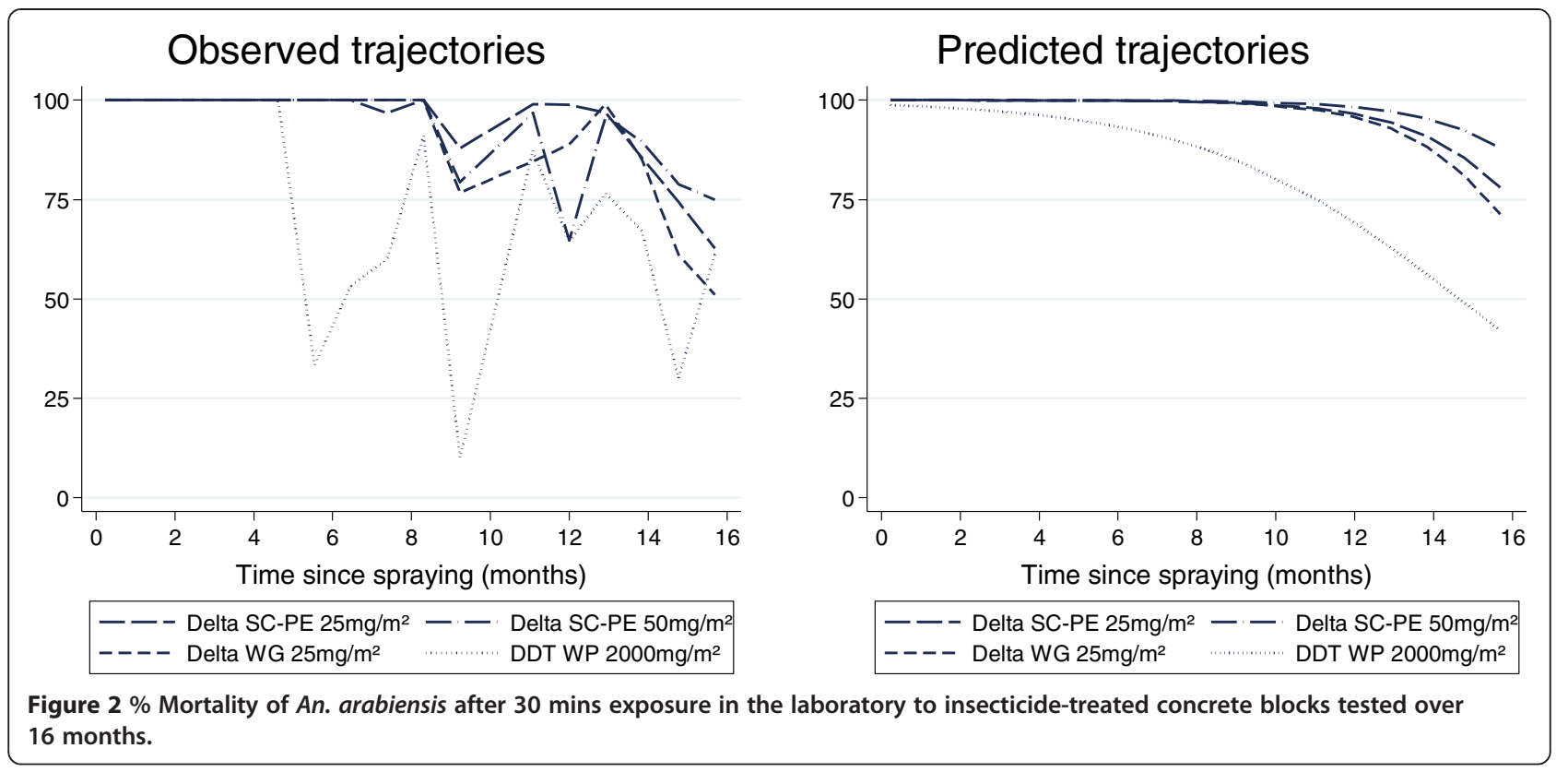

highest mortality shortly after spraying and a trend of declining insecticidal activity over time (Figures 3 , and 4 ).

Climate data recorded at the field station (USB Wireless Touchscreen Weather Forecaster, Maplin, UK) showed that mean night temperature (from 20:30 to $6: 30 \mathrm{~h}$ ) was lowest during the cool season between June-September, 3-6 months after spraying, with indoor temperature $\sim 24-25^{\circ} \mathrm{C}$ and outdoor $\sim 20-21^{\circ} \mathrm{C}$ (Figure 6). After accounting for mortality trajectories over time, there was no evidence of any association between overnight temperature or humidity and mortality $(\mathrm{P}>0.05)$. The number of $A n$. arabiensis collected per day from huts was dependent on rice cropping cycles with peak numbers occurring between July and October (Figure 7).

Percentage blood-feeding was high in the unsprayed hut but varied by month between $46-98 \%$ (Table 4); the rate was lowest during August when mosquito densities were highest. All IRS treatments provided a considerable degree of

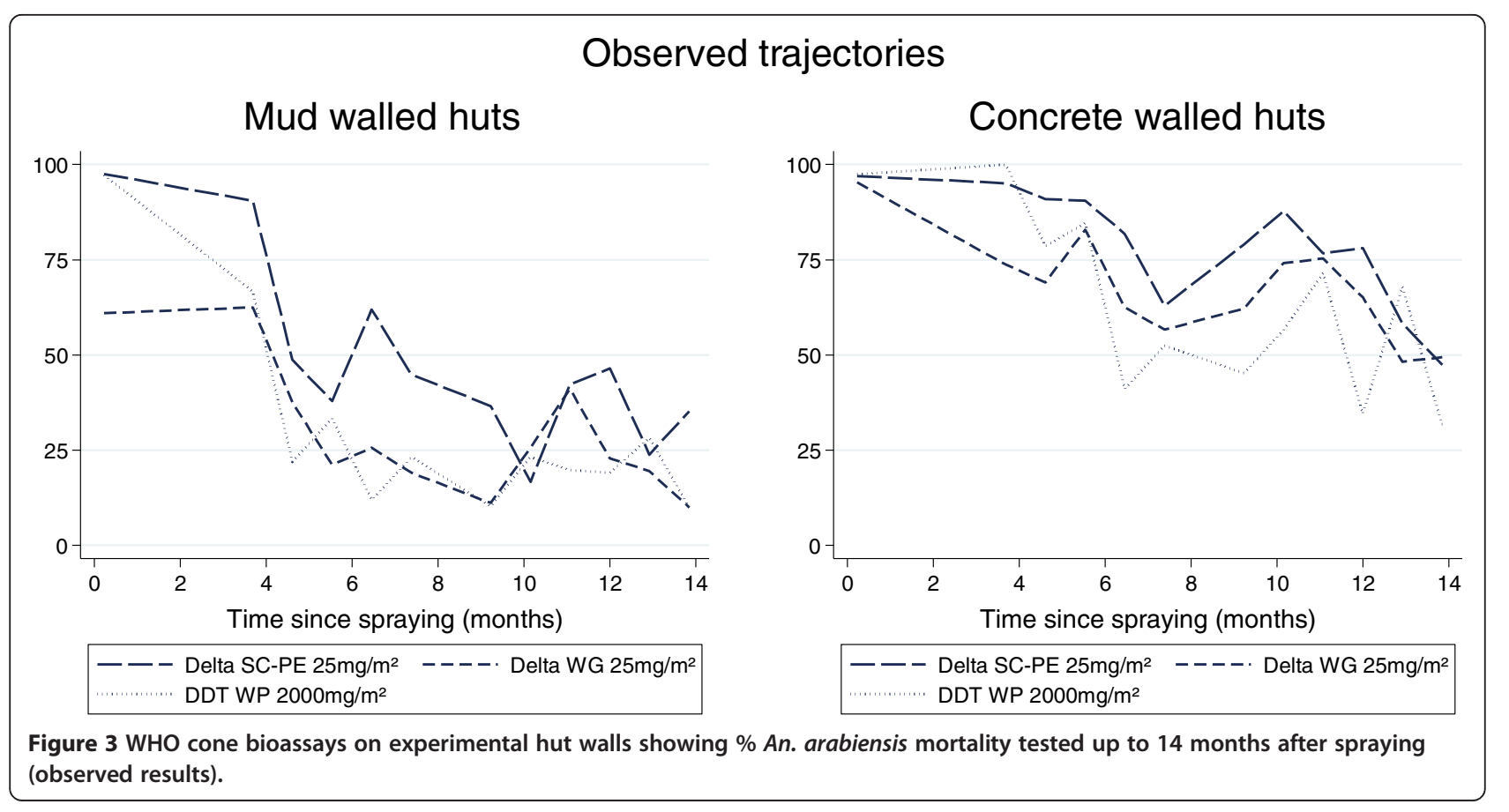




\section{Predicted trajectories}

\section{Mud walled huts}

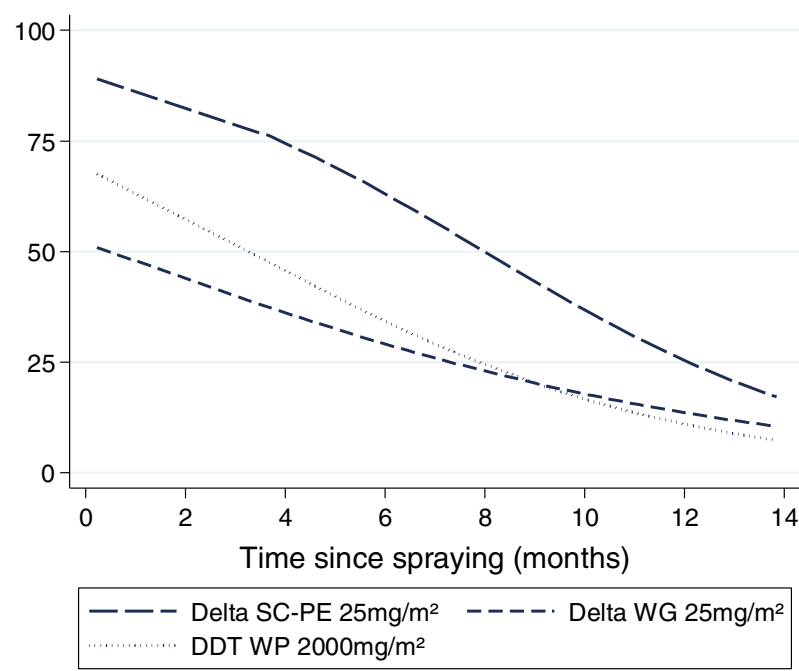

Concrete walled huts

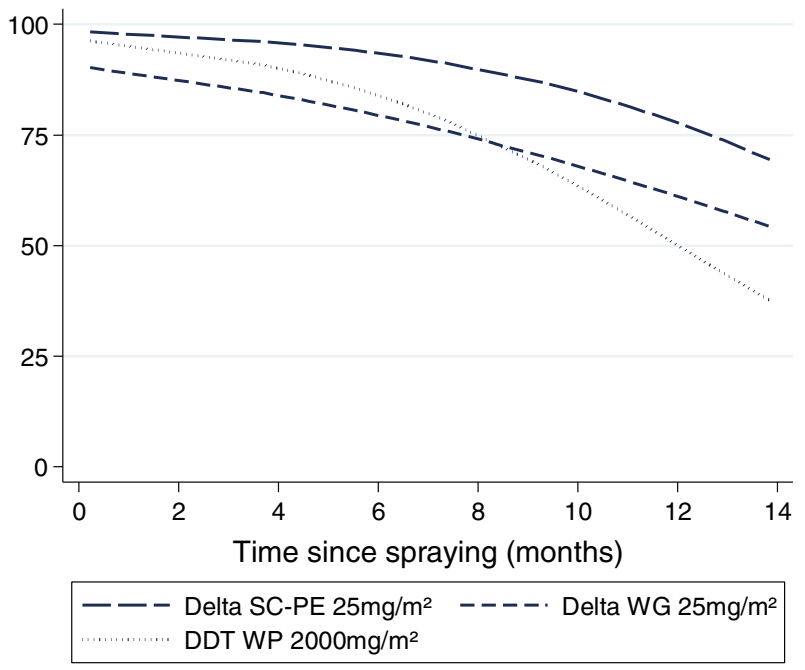

Figure 4 WHO cone bioassays on experimental hut walls showing \% An. arabiensis mortality tested up to 14 months after spraying (predicted results).

personal protection, but the degree of protection varied over time. Peak blood-feeding inhibition was in July (four months after spraying) and ranged between $66-71 \%$ by treatment compared to the unsprayed control. Over the nine month trial $76-80 \%$ of $A n$. arabiensis killed by the three treatments were unfed. The number of mosquitoes collected over the trial was substantially lower in the unsprayed control at 790 An. arabiensis females, compared with 1970 (mud) and
2293 (concrete) for delta SC-PE 25; 2034 (mud) and 2135 (concrete) delta WG 25; and 2009 (mud) and 2450 (concrete) for DDT. This probably indicates that a proportion of live mosquitoes were able to exit through open eaves. Insecticide-induced mortality in sprayed huts is likely to have limited the number of escapees. This should not affect the proportional comparisons between treatment, but may affect the overall mortality rates.
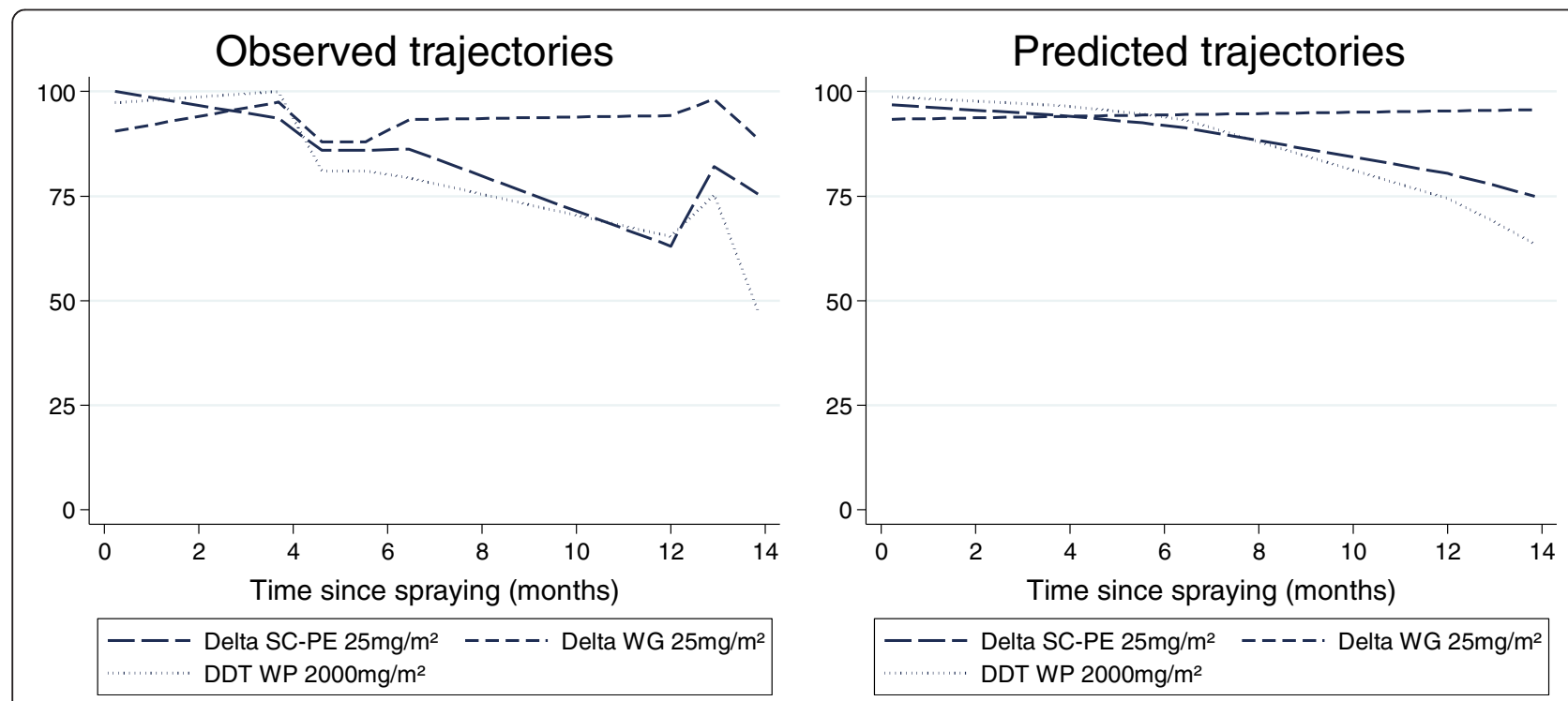

Figure 5 WHO cone bioassays on experimental hut ceiling showing \% An. arabiensis mortality tested 14 months after spray application. 


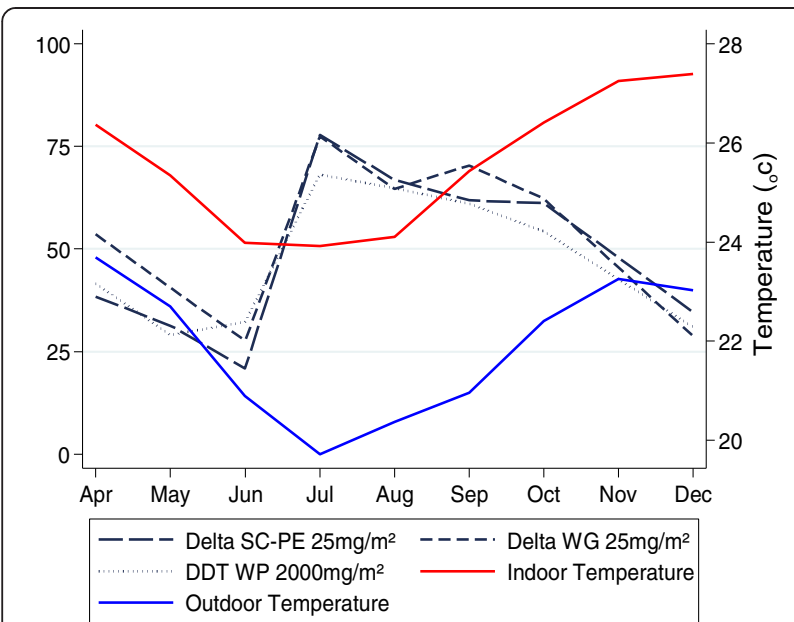

Figure 6 Trend of mean monthly temperature at the experimental hut site in relation to percentage mortality with DDT, deltamethrin WG and SC-PE. Notes: No data was collected for November. Data was combined for mud \& concrete walled huts and presented by treatment.

\section{Supplementary explanatory experimental hut testing}

Bioassays in experimental huts (Figure 5) indicated high levels of mortality (>80\%) for all formulations on palm thatch ceiling nine months after spraying, but much lower mortality for concrete and mud walls (Figures 3, and 4). Mortality achieved through mosquitoes contacting the palm thatch ceiling may have masked any differences in performance of wall substrates. Between 11-15 months after spraying a weekly rotation was done in all huts to cover/uncover the palm thatch ceiling with untreated plastic sheeting. Results are presented in Table 5. Surprisingly, covering the ceiling had no significant effect on \% mortality for all formulations and substrates tested $(\mathrm{P}=0.133$ 0.731). Between months 16-17 after spraying, the walls and ceiling of all mud-walled huts were covered with unsprayed plastic sheeting, while concrete-walled huts were left uncovered. This was done to investigate the possibility that mosquitoes may have been exiting other huts (with concrete walls) having picked up a lethal dosage of insecticide and dying in a nearby hut. Mortality was 3\% for all three treated huts with covered walls and ceiling, $2 \%$ in the unsprayed control, but in uncovered concrete-walled huts mortality was $41 \%, 44 \%$, and $42 \%$ respectively for delta SC-PE 25, WG 25, and DDT (Table 5). After 18 months the plastic sheeting was removed and mortality in the mud-walled huts returned to levels seen previously at $42 \%, 36 \%$, and $36 \%$ respectively, indicating that mortality was caused by the treated surfaces in each individual hut and not as a result of mosquito movement.

\section{Discussion}

The delta SC-PE 50 formulation was only tested in laboratory bioassays but showed improved longevity over delta SC-PE 25 and WG. This improved longevity over SC-PE 25 was most likely dosage related. The primary objective of this study was to determine whether delta SC-PE 25 formulation would achieve greater longevity than delta WG 25 and DDT WP when sprayed as IRS. Cone tests conducted on laboratory sprayed blocks showed that delta SC-PE 25 performed no better than the WG 25 formulation on mud, plywood and concrete substrates. In experimental hut and simple hut cone bioassays SC-PE 25 was significantly longer lasting than WG 25 on mud and concrete substrates but not on palm thatch or plywood.

Delta SC-PE 25 and WG 25 both lasted marginally longer than DDT in laboratory bioassays on mud and concrete and in simple hut bioassays on mud, concrete, palm thatch, and plywood.

In experimental hut cone tests over 14 months the delta SC-PE outperformed DDT on mud and concrete walls. Despite the majority of bioassay results indicating the SCPE and WG outperformed DDT, there was no difference in performance against wild free-flying An. arabiensis. Delta SC-PE, WG 25 and DDT were equivalent and produced effective control of An. arabiensis for several months. Cone tests on hut walls indicated a gradual decline in mortality on concrete and a much more rapid decline on mud walls for delta SC-PE 25, WG 25 and DDT. The loss of activity on mud walls could have been masked by greater residual activity on the sprayed palm thatch ceiling, as thatch killed high proportions in cone tests 12 months after spraying. However, covering of the ceiling between months 11-15 with untreated plastic sheeting produced no difference in mortality, and indicated that the sprayed walls were still making a significant contribution to mortality. Further supplementary tests covering both the walls and ceiling of selected huts indicated that mortality was being caused by mosquitoes resting on walls and ceiling and ruled out the possibility of mosquitoes flying between huts before dying. Nevertheless, this raises an important issue surrounding substrates used in experimental hut IRS trials. Usually spraying is done on multiple substrates (walls, ceiling, and door) in the same experimental hut but the performance on a more favourable substrate (eg. palm thatch) may mask poor performance on another (eg. mud) [29]. Recent studies of house design indicated that ceilings are not common in some rural areas of Africa [41,42]. It was also observed during a recent IRS campaign near Lake Victoria, Tanzania that only the walls were routinely sprayed, while the roof beams were left unsprayed (when no ceiling was present) (Oxborough, personal observation). Therefore, it is critically important to determine the performance of new insecticides in experimental huts where only one substrate is sprayed and WHOPES guidelines may need updating accordingly. 
Table 4 Experimental hut summary results for wild free-flying An. Arabiensis during the 9 month efficacy trial

\begin{tabular}{|c|c|c|c|c|c|c|c|c|c|}
\hline \multirow[t]{2}{*}{ Insecticide (Wall) substrate) } & \multirow[t]{2}{*}{ Outcome measure } & \multicolumn{8}{|c|}{ Time after spraying (months) } \\
\hline & & April & May & June & July & August & September & October & December \\
\hline \multirow[t]{5}{*}{ Delta SC-PE 25 mg/m² (Mud) } & Number Collected & 76 & 88 & 69 & 252 & 791 & 439 & 225 & 30 \\
\hline & \% Mortality & 28 & 34 & 13 & 75 & 66 & 59 & 56 & 37 \\
\hline & $95 \% \mathrm{Cl}$ & $19-39$ & $25-45$ & $7-23$ & $70-80$ & $62-69$ & $54-63$ & $49-62$ & $22-55$ \\
\hline & $\%$ Blood-fed & 71 & 64 & 36 & 19 & 21 & 31 & 39 & 53 \\
\hline & $\%$ Blood-feeding inhibition & 19 & 35 & 60 & 68 & 54 & 58 & 45 & 45 \\
\hline \multirow[t]{5}{*}{ Delta WG 25 mg/m² (Mud) } & Number Collected & 65 & 88 & 32 & 338 & 850 & 397 & 234 & 30 \\
\hline & $\%$ Mortality & 40 & 43 & 19 & 72 & 67 & 71 & 63 & 23 \\
\hline & $95 \% \mathrm{Cl}$ & $29-52$ & $33-54$ & $9-36$ & $67-77$ & $64-70$ & $66-75$ & $56-69$ & $12-42$ \\
\hline & $\%$ Blood-fed & 77 & 52 & 34 & 17 & 25 & 21 & 27 & 80 \\
\hline & $\%$ Blood-feeding inhibition & 13 & 47 & 62 & 71 & 46 & 71 & 62 & 17 \\
\hline \multirow[t]{5}{*}{ DDT WP 2000 mg/m² (Mud) } & Number Collected & 20 & 48 & 102 & 348 & 850 & 444 & 174 & 23 \\
\hline & $\%$ Mortality & 40 & 29 & 30 & 66 & 70 & 60 & 59 & 44 \\
\hline & $95 \% \mathrm{Cl}$ & $21-62$ & $18-43$ & $22-40$ & $61-71$ & $67-73$ & $56-65$ & $52-66$ & $25-64$ \\
\hline & $\%$ Blood-fed & 60 & 42 & 37 & 20 & 29 & 33 & 33 & 61 \\
\hline & $\%$ Blood-feeding inhibition & 32 & 57 & 58 & 66 & 37 & 55 & 54 & 36 \\
\hline \multirow[t]{5}{*}{ Delta SC-PE $25 \mathrm{mg} / \mathrm{m}^{2}$ (Concrete) } & Number Collected & 83 & 94 & 103 & 343 & 937 & 476 & 200 & 57 \\
\hline & $\%$ Mortality & 48 & 29 & 26 & 80 & 68 & 65 & 67 & 28 \\
\hline & $95 \% \mathrm{Cl}$ & $38-59$ & 21-39 & $19-36$ & $75-84$ & $65-71$ & $60-69$ & $60-73$ & $18-41$ \\
\hline & $\%$ Blood-fed & 75 & 67 & 53 & 20 & 22 & 31 & 36 & 39 \\
\hline & $\%$ Blood-feeding inhibition & 15 & 32 & 40 & 66 & 52 & 58 & 49 & 59 \\
\hline \multirow[t]{5}{*}{ Delta WG 25 mg/m² (Concrete) } & Number Collected & 75 & 65 & 44 & 323 & 947 & 383 & 272 & 26 \\
\hline & $\%$ Mortality & 65 & 37 & 34 & 83 & 62 & 70 & 62 & 39 \\
\hline & $95 \% \mathrm{Cl}$ & $54-75$ & $26-49$ & $22-49$ & $79-87$ & $59-65$ & $65-74$ & $56-67$ & $22-58$ \\
\hline & $\%$ Blood-fed & 64 & 49 & 48 & 17 & 19 & 22 & 33 & 23 \\
\hline & $\%$ Blood-feeding inhibition & 27 & 50 & 46 & 71 & 59 & 70 & 54 & 76 \\
\hline \multirow[t]{5}{*}{ DDT WP 2000 mg/m² (Concrete) } & Number Collected & 69 & 83 & 109 & 371 & 1105 & 454 & 233 & 26 \\
\hline & \% Mortality & 42 & 29 & 34 & 70 & 61 & 62 & 51 & 27 \\
\hline & $95 \% \mathrm{Cl}$ & $31-54$ & $20-40$ & $26-43$ & $66-75$ & $58-64$ & $57-66$ & $44-57$ & $13-47$ \\
\hline & $\%$ Blood-fed & 59 & 61 & 47 & 18 & 21 & 28 & 34 & 54 \\
\hline & $\%$ Blood-feeding inhibition & 33 & 38 & 47 & 69 & 54 & 62 & 52 & 44 \\
\hline \multirow[t]{4}{*}{ Untreated (Mud) } & Number Collected & 50 & 57 & 47 & 161 & 255 & 111 & 86 & 23 \\
\hline & $\%$ Mortality & 16 & 4 & 6 & 17 & 11 & 2 & 1 & 4 \\
\hline & $95 \% \mathrm{Cl}$ & $8-29$ & $1-13$ & $2-18$ & $12-24$ & $7-15$ & $1-7$ & $0-8$ & $1-25$ \\
\hline & $\%$ Blood-fed & 88 & 98 & 89 & 59 & 46 & 73 & 71 & 96 \\
\hline
\end{tabular}

The mortality trends for wild free-flying An. arabiensis were unexpected and appear to be influenced by factors other than insecticide sorption and degradation. Nevertheless, the overall trends were maintained within insecticide formulations throughout the trial. The reasons for seasonal fluctuations in mortality are most likely, in part, related to changes of temperature, although a clear correlation could not be shown. DDT and pyrethroid insecticides interfere with sodium and potassium conductance through nerve membranes and both show a negative temperature coefficient with toxicity for the majority of insect species evaluated including Anopheles mosquitoes [43,44], cockroaches [45-47], tsetse flies [48], stored grain pests [49], and houseflies [50,51]. This appears to be due to greater nerve sensitivity as insecticide penetration is conversely greater at higher temperature [50].

Residual house spraying is only effective if the mosquito species concerned is endophilic and rests on the 


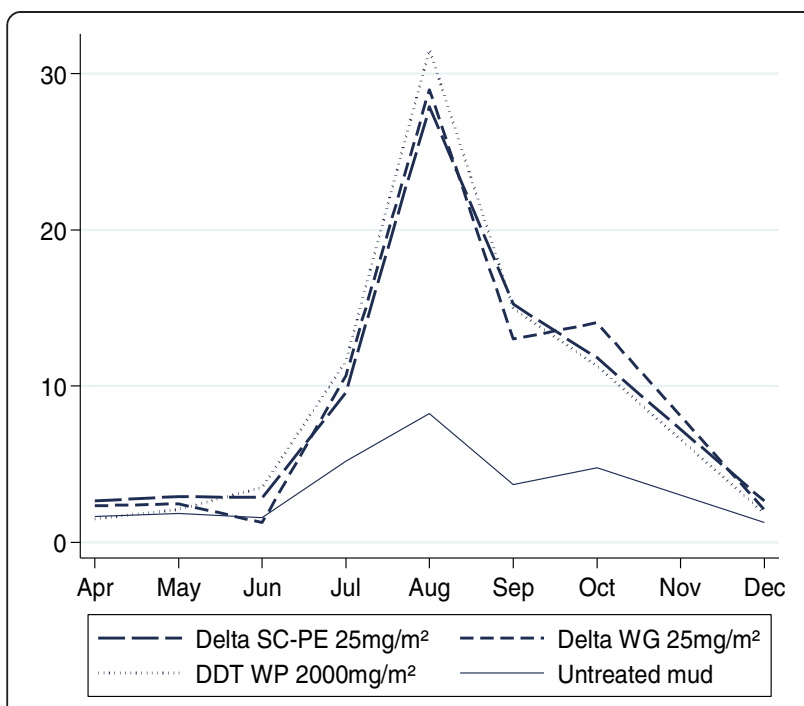

Figure 7 Mean number of mosquitoes collected per night for experimental huts sprayed with DDT, deltamethrin WG and SC-PE.

Notes: No data was collected for November. Data was combined for mud \& concrete walled huts and presented by treatment.

insecticide-treated surfaces for a sufficient time to pick up a lethal dose [52]. Changes in resting behaviour in response to seasonal changes in climate may have an important bearing on efficacy. An. gambiae gonotrophic cycle duration is closely correlated with temperature and it is likely that selecting a warmer microclimate while processing a blood-meal to eggs is advantageous in terms of natural selection [53]. At higher altitude where differences between indoor and outdoor temperature are greatest, indoor resting is more common [54-56]. It is conceivable that when outdoor temperature is low, IRS becomes more effective, due to mosquitoes spending relatively longer time resting on treated surfaces indoors. Resting behaviour appears to be relatively plastic, particularly for An. arabiensis [54], and may change according to season. As there was no straightforward statistical correlation between temperature and mortality, it is likely that several factors were involved, which could not be fully explained by this study. The initial high dosage of insecticide shortly after spraying may have partially overridden any temperature-related effects on mortality. Excito-repellent behaviour caused by DDT and deltamethrin is another factor, which will undoubtedly have had an impact on resting times on treated surfaces and time of exiting $[57,58]$.

The months of highest percentage mortality coincided with the months of highest mosquito density when the rice fields were flooded and at their most productive. The high densities entering the huts in July-August would have been younger than at the tail end of the previous cropping season (April-June) when mortality was notably lower. There is an association between resistance to pyrethroids and age of adult mosquitoes, but the relationship is an inverse one, with mosquitoes tending to show reduced resistance as they get older. An arabiensis from Lower Moshi shows low grade metabolic resistance to permethrin and deltamethrin associated with increased expression of CYP4G16 oxidases and ABC2060 transporters [39,59] and studies on An. gambiae which carry CYP4G16 and other cytochrome P450s show greatest resistance when they are young [60]. The trends in this study are the opposite of what one might expect to see from a young population and so the explanation must lie elsewhere.

Most experimental hut studies of IRS insecticides have been done over a short duration of 2-3 months. The duration of this study has identified long-term factors, such as climate, which should be considered and investigated in more detail. This may have wider implications to national control programs that conduct IRS and highlights the need for proper monitoring of vector control interventions. In this study the low levels of mortality recorded between 1-3 months after spraying correlated with a time when mosquito numbers were relatively low, while peak mortality occurred when mosquito numbers were highest. If a temporary loss of control occurs for reasons other than insecticide decay, it is likely to be of minimal consequence so long as IRS is effective during peak mosquito and malaria transmission seasons.

According to WHOPES, DDT has the greatest longevity of all IRS recommended insecticides, with a duration of effective action of $>6$ months [17]. Delta WG is considered by WHOPES to be inferior to DDT with a residual action of 3-6 months. In this study both delta SCPE and WG 25 formulations were equivalent or better than DDT in hut trials and cone bioassays. The Stockholm Convention on persistent organic pollutants came into effect in 2004 and stipulates that 'countries using DDT are encouraged to reduce and eliminate the use of DDT over time and switch to alternative insecticides' [18]. Despite this international agreement, global use of DDT has not changed substantially [16]. DDT is still used mainly due to longevity and low cost. The present study has shown that delta SC-PE or WG are comparable with DDT in terms of longevity. Delta WG is relatively inexpensive (and is not subject to the same additional costs for environmental management as DDT) and the overall cost of spray operations in Africa using deltamethrin or DDT have been shown to be comparable [61].

Pyrethroid use in Africa for IRS and LLIN has increased greatly between 2002- 2013 [16] and has probably accelerated the development and spread of pyrethroid resistance $[62,63]$. Of 17 African countries sprayed within the President's Malaria Initiative (PMI)-funded IRS in 2012, only one was classified as having pyrethroid susceptible 
Table 5 Experimental hut summary results for wild free-flying An. arabiensis during the supplementary experiments

\begin{tabular}{|c|c|c|c|c|c|}
\hline \multirow[t]{2}{*}{ Insecticide (wall substrate) } & \multirow[t]{2}{*}{ Outcome measure } & \multicolumn{4}{|c|}{ Number of months after spraying } \\
\hline & & $11-15$ uncovered & 11-15 ceiling covered & $\begin{array}{l}16-17 \text { walls and } \\
\text { ceiling covered } \dagger\end{array}$ & 18 uncovered \\
\hline \multirow[t]{5}{*}{ Delta SC-PE 25 mg/m² (Mud) } & Number collected & 365 & 499 & 521 & 183 \\
\hline & $\%$ Mortality & 41 & 37 & $3+$ & 42 \\
\hline & $95 \% \mathrm{Cl}$ & $31-52$ & $28-48$ & $1-6$ & $35-50$ \\
\hline & $\%$ Blood-fed & 40 & 36 & 56 & 32 \\
\hline & $\%$ Blood-feeding inhibition & 42 & 33 & 5 & 20 \\
\hline \multirow[t]{5}{*}{ Delta WG 25 mg/m² (Mud) } & Number collected & 300 & 559 & 463 & 130 \\
\hline & $\%$ Mortality & 46 & 33 & $3+$ & 36 \\
\hline & $95 \% \mathrm{Cl}$ & $31-61$ & $24-43$ & $1-7$ & $28-45$ \\
\hline & $\%$ Blood-fed & 45 & 29 & 51 & 33 \\
\hline & $\%$ Blood-feeding inhibition & 35 & 46 & 14 & 18 \\
\hline \multirow[t]{5}{*}{ DDT WP 2000 mg/m² (Mud) } & Number collected & 218 & 305 & 190 & 214 \\
\hline & $\%$ Mortality & 51 & 37 & $3+$ & 36 \\
\hline & $95 \% \mathrm{Cl}$ & $39-62$ & $25-52$ & $1-11$ & $28-45$ \\
\hline & $\%$ Blood-fed & 35 & 37 & 80 & 38 \\
\hline & $\%$ Blood-feeding inhibition & 49 & 32 & 0 & 3 \\
\hline \multirow[t]{5}{*}{ Delta SC-PE 25 mg/m² (Concrete) } & Number collected & 373 & 659 & 715 & 160 \\
\hline & $\%$ Mortality & 28 & 37 & 41 & 39 \\
\hline & $95 \% \mathrm{Cl}$ & $22-34$ & $28-48$ & $34-48$ & $30-49$ \\
\hline & $\%$ Blood-fed & 48 & 39 & 52 & 43 \\
\hline & $\%$ Blood-feeding inhibition & 30 & 28 & 12 & 0 \\
\hline \multirow[t]{5}{*}{ Delta WG 25 mg/m² (Concrete) } & Number collected & 310 & 528 & 759 & 152 \\
\hline & $\%$ Mortality & 41 & 37 & 44 & 42 \\
\hline & $95 \% \mathrm{Cl}$ & $27-57$ & $30-44$ & $37-52$ & $33-52$ \\
\hline & $\%$ Blood-fed & 32 & 32 & 56 & 39 \\
\hline & $\%$ Blood-feeding inhibition & 54 & 41 & 5 & 3 \\
\hline \multirow[t]{5}{*}{ DDT WP 2000 mg/m² (Concrete) } & Number collected & 262 & 508 & 705 & 174 \\
\hline & $\%$ Mortality & 49 & 44 & 42 & 40 \\
\hline & $95 \% \mathrm{Cl}$ & $37-61$ & $34-54$ & $35-48$ & $28-52$ \\
\hline & $\%$ Blood-fed & 44 & 34 & 58 & 33 \\
\hline & $\%$ Blood-feeding inhibition & 36 & 37 & 2 & 18 \\
\hline \multirow[t]{4}{*}{ Untreated (Mud) } & Number collected & 276 & 369 & 376 & 98 \\
\hline & $\%$ Mortality & 7 & 12 & $2+$ & 2 \\
\hline & $95 \% \mathrm{Cl}$ & $3-16$ & $7-19$ & $0-7$ & $1-8$ \\
\hline & $\%$ Blood-fed & 69 & 54 & 59 & 40 \\
\hline
\end{tabular}

Notes: IIndicates that the sprayed walls and ceiling of the experimental hut were covered with untreated plastic sheeting.

anophelines; the remainder had confirmed or emerging resistance [64]. WHO recommends that in areas of high LLIN coverage, pyrethroid insecticides should not be used for IRS as this will contribute to selection pressure [65]. This strategy has been adopted by some national control programmes, such as in Senegal, where pyrethroids are advocated for LLIN but not IRS, for better resistance management [66]. The long term strategy is to reduce reliance on the persistent organic pollutant (POP) DDT [18] and to reduce selection pressure on LLINs by reducing pyrethroid IRS use [65]. However, there is currently a shortage of alternative insecticides for IRS [22,23], and pyrethroid insecticides are likely to have an important role as part of a rotation strategy with one or more different insecticide classes rotated annually; particularly in areas that currently have low 
levels of pyrethroid resistance [65] or low LLIN coverage, such as India. The level of insecticide resistance at which effectiveness is compromised remains unknown and there is evidence to suggest that pyrethroids can reduce sporozoite rates by killing older mosquitoes, which become less resistant with age $[60,67]$. Deltamethrin SC-PE recently received recommendation by WHO for IRS at a dosage of $20-25 \mathrm{mg} / \mathrm{m}^{2}$, with an expected residual efficacy of 6 months [25].

\section{Conclusions}

Deltamethrin IRS should be used judiciously as part of a resistance management strategy in rotation with other classes of IRS such as bendiocarb $[68,69]$ and pirimiphosmethyl CS $[26,70]$ according to GPIRM $[14,65]$.

\section{Competing interests}

The authors declare that they have no competing interests.

\section{Authors' contributions}

RMO participated in the trial design, oversaw collection of data, conducted preliminary data analysis, interpreted the data and wrote the manuscript. JK supervised data collection, conducted spraying, and was involved in data interpretation. RJ conducted statistical analysis for all data presented in the paper. FWM was involved in trial design and data interpretation. MWR conceived the study, participated in the design, interpretation of results and improved the manuscript. All authors read and approved the final manuscript.

\section{Acknowledgements}

RMO and MR are members of the Malaria Centre of the London School of Hygiene and Tropical Medicine, http:/malaria.lshtm.ac.uk/. The authors thank Dave Malone and Robert Sloss for technical programme support (IVCC, Liverpool, UK). The authors thank Drs Karin Horn, Volker Gutsmann, and Justin McBeath (Bayer CropScience, Monheim, Germany) for supplying samples and for technical input. We are grateful to E Feston, C Masenga, A Mtui, E Philipo, E Tilya, H Temba, P Anthony, J Mpuya, R Athuman, K Ezekia, R Mndeme, G Chuwa, E Macha, A Tumaini; for insectary, field, and administrative assistance.

\section{Author details}

'Department of Disease Control, London School of Hygiene and Tropical Medicine (LSHTM), London, UK. ${ }^{2}$ Department of Entomology and Parasitology, Kilimanjaro Christian Medical University College (KCMUCo) of Tumaini University, Moshi, Kilimanjaro, Tanzania. ${ }^{3}$ Department of Entomology, Pan-African Malaria Vector Research Consortium, (PAMVERC), Moshi, Kilimanjaro, Tanzania.

Received: 11 June 2014 Accepted: 20 September 2014

Published online: 02 October 2014

\section{References}

1. Pluess $B$, Tanser FC, Lengeler C, Sharp BL: Indoor residual spraying for preventing malaria. Coch Data Syst Rev 2010, 1-47.

2. Beer N, Ali AS, Shakely D, Elfving K, Al-Mafazy AW, Msellem M, Petzold M, Bjorkman A, Kallander K: High effective coverage of vector control interventions in children after achieving low malaria transmission in Zanzibar, Tanzania. Malar J 2013, 12:38.

3. Overgaard HJ, Reddy VP, Abaga S, Matias A, Reddy MR, Kulkarni V, Schwabe C, Segura L, Kleinschmidt I, Slotman MA: Malaria transmission after five years of vector control on Bioko Island, Equatorial Guinea. Parasit Vectors 2012, 5:253.

4. WHO: Global malaria control \& elimination; report of a technical review. 2008.

5. RBM: Eliminating malaria: learning from the past, looking ahead. WHO Prog Imp Series 2011, ISBN 9789241502504.

6. WHO: Implementation of indoor residual spraying of insecticides for malaria control in the WHO African Region Report. 2007,
7. Mabaso ML, Sharp B, Lengeler C: Historical review of malarial control in southern African with emphasis on the use of indoor residual house-spraying. Trop Med Int Health 2004, 9:846-856.

8. WHO: Indoor residual spraying; use of indoor residual spraying for scaling up global malaria control and elimination. 2006, WHO/HTM/MAL/ 2006.1112.

9. USAID: Lantos-Hyde United States Government Malaria Strategy 2009-2014. http://www.pmi.gov/docs/default-source/default-document-library/pmireports/ usg_strategy2009-2014.pdf?sfvrsn=13 2010:1-17.

10. WHO: WHO global programme world malaria report 2013. 2013,

11. Bhattarai A, Ali AS, Kachur SP, Martensson A, Abbas AK, Khatib R, Al-Mafazy AW, Ramsan M, Rotllant G, Gerstenmaier JF, Molteni F, Abdulla S, Montgomery SM, Kaneko A, Bjorkman A: Impact of artemisinin-based combination therapy and insecticide-treated nets on malaria burden in Zanzibar. PLoS Med 2007, 4:e309.

12. Tseng LF, Chang WC, Ferreira MC, Wu CH, Rampao HS, Lien JC: Rapid control of malaria by means of indoor residual spraying of alphacypermethrin in the democratic republic of Sao tome and Principe. Am J Trop Med Hyg 2008, 78:248-250.

13. PMI: IRS insecticide use and forecast for 2014. 2013. [http://www.pmi.gov/ docs/default-source/default-document-library/toolscurricula/pmi_irs_ insecticide_trends.xlsx?sfursn=12] 2013.

14. Hemingway J, Vontas J, Poupardin R, Raman J, Lines J, Schwabe C, Matias A, Kleinschmidt I: Country-level operational implementation of the global plan for insecticide resistance management. Proc Natl Acad Sci U S A 2013, 110:9397-9402.

15. WHO: Malaria situation in India, 2010. 2010,

16. Van den Berg H, Zaim M, Yadav R, Soares A, Ameneshewa B, Mnzava AE, Hii J, Dash AP, Ejov M: Global trends in the use of insecticides for vector-borne disease control. Environ Health Pers 2012, 120(4):577-582.

17. WHO: WHO recommended insecticides for indoor residual spraying against malaria vectors. http://www.who.int/whopes/ Insecticides_IRS_Malaria_25_Oct_2013.pdf?ua=1 2014.

18. U.N.E.P: Ridding the world of POPs: a guide to the Stockholm convention on persistent organic pollutants. 2010,

19. WHO: The use of DDT in malaria vector control. In WHO position statement. 2011. WHO/HTM/GMP/2011.

20. WHO: World malaria report 2011. 2011,

21. Abbott M, Johns B: PMI IRS country programs: comparative cost analysis, august 11, 2011 - december 31, 2012. Bethesda, MD: africa indoor residual spraying (AIRS) project, Abt associates Inc. 2013,

22. Hemingway J, Beaty BJ, Rowland M, Scott TW, Sharp BL: The innovative vector control consortium: improved control of mosquito-borne diseases. Trends Parasitol 2006, 22:308-312.

23. Zaim M, Guillet P: Alternative insecticides: an urgent need. Trends Parasitol 2002, 18:161-163.

24. Tsuji K: Microencapsulation of pesticides and their improved handling safety. J Microencapsul 2001, 18:137-147.

25. WHOPES: Report of the sixteenth WHOPES working group meeting WHO/HQ Geneva; review of pirimiphos-methyl 300CS, chlorfenapyr 240 SC, deltamethrin 62.5 SC-PE, Duranet LN, Netprotect LN, Yahe LN, Spinosad 83.3 monolayer DT, Spinosad 25 extended release GR. 2013,

26. Rowland M, Boko P, Odjo A, Asidi A, Akogbeto M, N'Guessan R: A new long-lasting indoor residual formulation of the organophosphate insecticide pirimiphos methyl for prolonged control of pyrethroid-resistant mosquitoes: an experimental hut trial in Benin. PLoS One 2013, 8:e69516.

27. WHO: WHO recommended insecticide products treatment of mosquito nets for malaria vector control. 2007, [http://www.who.int/whopes/ Insecticides_ITN_Malaria_ok3.pdf]

28. WHO: WHO recommended insecticides for indoor residual spraying against malaria vectors. 2013. [http://www.who.int/whopes/ Insecticides_IRS_Malaria_25_Oct_2013.pdf?ua=1] 2013.

29. WHO: Guidelines for testing mosquito adulticides for indoor residual spraying and treatment of mosquito nets. 2006, WHO/CDS/NTD/WHOPES/ GCDPP/2006.2003.

30. WHO: Manual for indoor residual spraying application of residual sprays for vector control. 2007, WHO/CDS/NTD/WHOPES/GCDPP/2007.2003.

31. Curtis CF, Myamba J, Wilkes TJ: Comparison of different insecticides and fabrics for anti-mosquito bednets and curtains. Med Vet Entomol 1996, 10:1-11.

32. Oxborough RM, Kitau J, Matowo J, Mndeme R, Feston E, Boko P, Odjo A, Metonnou CG, Irish S, N'Guessan R, Mosha FW, Rowland MW: Evaluation of 
indoor residual spraying with the pyrrole insecticide chlorfenapyr against pyrethroid-susceptible Anopheles arabiensis and pyrethroid-resistant Culex quinquefasciatus mosquitoes. Trans R Soc Trop Med Hyg 2010, 104:639-645.

33. Smith $A: A$ verandah-trap hut for studying the house-frequenting habits of mosquitos and for assessing insecticides. I: a description of the verandah-trap hut and of studies on the egress of Anopheles gambiae giles and Mansonia uniformis (Theo.) from an untreated hut. Bull Entomol Res 1965, 56:161-167.

34. Smith A, Webley DJ: A verandah-trap hut for studying the housefrequenting habits of mosquitoes and for assessing insecticides. 3: the effect of DDT on behavior and mortality. Bull Entomol Res 1969, 59:33-46.

35. Mosha FW, Lyimo IN, Oxborough RM, Malima R, Tenu F, Matowo J, Feston E, Mndeme R, Magesa SM, Rowland M: Experimental hut evaluation of the pyrrole insecticide chlorfenapyr on bed nets for the control of Anopheles arabiensis and Culex quinquefasciatus. Trop Med Int Health 2008, 13:644-652.

36. TDHS, ICF Macro: Tanzania Demographic and Health Survey 2010. National Bureau of Statistics, Dar es Salaam, Tanzania. Calverton, Maryland, USA: ICF Macro; 2011.

37. Kulkarni MA, Rowland M, Alifrangis M, Mosha FW, Matowo J, Malima R, Peter J, Kweka E, Lyimo I, Magesa S, Salanti A, Rau ME, Drakeley C: Occurrence of the leucine-to-phenylalanine knockdown resistance (kdr) mutation in Anopheles arabiensis populations in Tanzania, detected by a simplified high-throughput SSOP-ELISA method. Malar J 2006, 5:56.

38. Kitau J, Oxborough RM, Tungu PK, Matowo J, Malima RC, Magesa SM, Bruce $J$, Mosha FW, Rowland MW: Species shifts in the Anopheles gambiae complex: do LLINs successfully control Anopheles arabiensis? PLoS One 2012, 7:e31481.

39. Matowo J, Kitau J, Kabula B, Kavishe R, Oxborough R, Kaaya R, Francis P, Chambo A, Mosha F, Rowland M: Dynamics of insecticide resistance and the frequency of kdr mutation in the primary malaria vector Anopheles arabiensis in rural villages of Lower Moshi, North Eastern Tanzania. J Parasitol Vec Biol 2014, 6(3):31-41.

40. Mahande AM, Dusfour I, Matias JR, Kweka EJ: Knockdown resistance, rdl alleles, and the annual entomological inoculation rate of wild mosquito populations from lower Moshi, Northern Tanzania. J Glob Infect Dis 2012, 4:114-119.

41. Atieli $H$, Menya $D$, Githeko A, Scott T: House design modifications reduce indoor resting malaria vector densities in rice irrigation scheme area in western Kenya. Malar J 2009, 8:108

42. Schofield CJ, White GB: Engineering against insect-borne diseases in the domestic environment; house design and domestic vectors of disease. Trans R Soc Trop Med Hyg 1984, 78:285-292.

43. Hodjati MH, Curtis CF: Effects of permethrin at different temperatures on pyrethroid-resistant and susceptible strains of Anopheles. Med Vet Entomol 1999, 13:415-422.

44. Hadaway $A B$, Barlow $F$ : The influence of environmental conditions on the contact toxicity of some insecticide deposits to adult mosquitoes, Anopheles stephensi List. Bull Entomol Res 1963, 54:329-344.

45. Scott JG: Effect of temperature on the toxicity of 5-bioallethrin and cypermethrin to susceptible and kdr-resistant strains of Blattella germanica (L.) (Dictyoptera: Blattellidae). Bull Entomol Res 1987, 77:431-435.

46. Wadleigh RW, Koehler PG, Preisler HK, Patterson RS, Robertson JL: Effect of temperature on the toxicities of ten pyrethroids to German cockroach (Dictyoptera: Blattellidae). J Econ Entomol 1991, 84:1433-1436.

47. Eaton JL, Sternburg JG: Temperature effects of nerve activity in DDTtreated American cockroaches. J Econ Entomol 1967, 60:1358-1364.

48. Hadaway AB: Post-treatment temperature and the toxicity of some insecticides to tsetse flies. WHO 1979, 1-2. WHO/NBC/78.693.

49. Longstaff B, Desmarchelier J: The effects of the temperature-toxicity relationships of certain pesticides upon the population growth of Sitophilus oryzae (L.) (Coleoptera: Curculionidae). J Stored Prod Res 1983, 19:25-29.

50. Ahn Y, Shono T, Fukami J-l: Effect of temperature on pyrethroid action to kdr-type house fly adults. Pest Biochem Physiol 1987, 28:301-307.

51. Ansari J, Riaz N: Temperature coefficient of housefly resistance to insecticides. Kyoto Uni Bull 1965, 30(4):105-108.

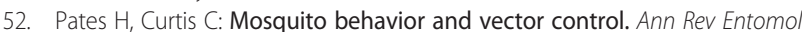
2005, 50:53-70

53. Afrane YA, Lawson BW, Githeko AK, Yan G: Effects of microclimatic changes caused by land use and land cover on duration of gonotrophic cycles of Anopheles gambiae (Diptera: Culicidae) in western Kenya highlands. J Med Entomol 2005, 42:974-980.

54. Paaijmans KP, Thomas MB: The influence of mosquito resting behaviour and associated microclimate for malaria risk. Malar J 2011, 10:183.

55. Manguin S: Biodiversity of Malaria in the world, English completely updated. edn. Montrouge; Esther [Esher]. John Libbey Eurotext: Surrey; 2008.

56. Tchuinkam T, Simard F, Lele-Defo E, Tene-Fossog B, Tateng-Ngouateu A, Antonio-Nkondjio C, Mpoame M, Toto JC, Njine T, Fontenille D, Awono-Ambene HP: Bionomics of Anopheline species and malaria transmission dynamics along an altitudinal transect in Western Cameroon. BMC Infect Dis 2010, 10:119.

57. Grieco JP, Achee NL, Andre RG, Roberts DR: A comparison study of house entering and exiting behavior of Anopheles vestitipennis (Diptera: Culicidae) using experimental huts sprayed with DDT or deltamethrin in the southern district of Toledo, Belize, C.A. J Vector Ecol 2000, 25:62-73.

58. Potikasikorn J, Chareonviriyaphap T, Bangs MJ, Prabaripai A: Behavioral responses to DDT and pyrethroids between Anopheles minimus species A and C, malaria vectors in Thailand. Am J Trop Med Hyg 2005, 73:343-349.

59. Matowo J, Jones CM, Kabula B, Ranson H, Steen K, Mosha F, Rowland M, Weetman D: Genetic basis of pyrethroid resistance in a population of Anopheles arabiensis, the primary malaria vector in Lower Moshi, north-eastern Tanzania. Parasit Vectors 2014, 7:274.

60. Jones CM, Sanou A, Guelbeogo WM, Sagnon N, Johnson PC, Ranson H: Aging partially restores the efficacy of malaria vector control in insecticide-resistant populations of Anopheles gambiae sl from Burkina Faso. Malar J 2012, 11:24.

61. Sadasivaiah S, Tozan Y, Breman JG: Dichlorodiphenyltrichloroethane (DDT) for indoor residual spraying in Africa: how can it be used for malaria control? Am J Trop Med Hyg 2007, 77:249-263.

62. Czeher C, Labbo R, Arzika I, Duchemin JB: Evidence of increasing Leu-Phe knockdown resistance mutation in Anopheles gambiae from Niger following a nationwide long-lasting insecticide-treated nets implementation. Malar J 2008, 7:189.

63. Ranson H, N'Guessan R, Lines J, Moiroux N, Nkuni Z, Corbel V: Pyrethroid resistance in African anopheline mosquitoes: what are the implications for malaria control? Trends Parasitol 2011, 27:91-98.

64. PMI: PMI actual and estimated use of insecticides for the indoor residual spraying program. 2012 [http://www.pmi.gov/docs/default-source/defaultdocument-library/toolscurricula/pmi_irs_insecticide_trends.xlsx?sfvrsn=12]

65. WHO: The Global Plan for Insecticide Resistance Management in Malaria Vectors (GPIRM). 2012

66. President's Malaria Initiative: Africa Indoor Residual Spraying project. Semi-annual Report: October 2012-March 2013. Bethesda: MD AIRS, Abt Associates Inc; 2013.

67. Sharp BL, Ridl FC, Govender D, Kuklinski J, Kleinschmidt I: Malaria vector control by indoor residual insecticide spraying on the tropical island of Bioko. Equatorial Guinea Malar J 2007, 6:52.

68. Akogbeto MC, Padonou GG, Gbenou D, Irish S, Yadouleton A: Bendiocarb, a potential alternative against pyrethroid resistant Anopheles gambiae in Benin. West Africa Malar J 2010, 9:204.

69. Akogbeto M, Padonou GG, Bankole HS, Gazard DK, Gbedjissi GL: Dramatic decrease in malaria transmission after large-scale indoor residual spraying with bendiocarb in Benin, an area of high resistance of Anopheles gambiae to pyrethroids. Am J Trop Med Hyg 2011, 85:586-593.

70. Rowland MW, Boko P, Odjo A, Asidi A, Akogbeto M, N'Guessan R: A new long-lasting indoor residual insecticide, pirimiphos methyl, for prolonged malaria transmission control against pyrethroid-resistant mosquitoes: an experimental hut trial in Benin. Plos One 2013,

doi:10.1186/s13071-014-0454-1

Cite this article as: Oxborough et al.: Experimental hut and bioassay evaluation of the residual activity of a polymer-enhanced suspension concentrate (SC-PE) formulation of deltamethrin for IRS use in the control of Anopheles arabiensis. Parasites \& Vectors 2014 7:454. 